\title{
Práticas Socioambientais nas Empresas do Município de Sousa, PB: Contribuições ao Desenvolvimento Local Sustentável
}

\section{Social and Environmental Practices in Companies of the City of Sousa, PB: Contributions to Sustainable Local Development}

\author{
Maria de Fátima Nóbrega Barbosa \\ Professora Doutora da Unidade Acadêmica de Ciências Contábeis da UFCG. \\ Endereço: Rua, Sinfrônio Nazaré, 38, Centro, Sousa, PB, CEP: 58.240-000, fone: (83) 3521-3200 \\ e-mail: $\underline{\text { mfnbarbosa@hotmail.com }}$ \\ Danilo Gonçalves Rodrigues \\ Graduando em Administração - UACC/CCJS/UFCG \\ Endereço: Rua, Sinfrônio Nazaré, 38, Centro, Sousa, PB, CEP: 58.240-000, fone: (83) 3521-3200 \\ e-mail: dangr.15@hotmail.com
}

\section{Erivaldo Moreira Barbosa}

Professor Doutor da Unidade Acadêmica de Direito - UAD/CCJS/UFCG e do PPGRN/UFCG. Endereço: Rua, Sinfrônio Nazaré, 38, Centro, Sousa, PB, CEP: 58.240-000, fone: (83) 3521-3200

e-mail: $\underline{\text { mfnbarbosa@hotmail.com }}$

\begin{abstract}
RESUMO
As pressões sociais, econômicas, políticas, institucionais e éticas vêm exigindo mudanças significativas nas organizações em suas relações com o meio ambiente. Neste novo ambiente estabelecido exige-se uma postura proativa das empresas em relação a sua conduta ambiental e social. Neste contexto, este artigo tem como objetivo geral identificar as práticas socioambientais em empresas potencialmente poluidoras ou utilizadoras de recursos ambientais no município de Sousa - PB. De forma específica pretende: verificar as possíveis ferramentas e modelos ambientais (práticas socioambientais) utilizados pelas empresas; identificar a estratégia ambiental adotada pelas empresas e descrever a percepção de alguns stakeholders acerca das práticas socioambientais das empresas e da sustentabilidade do município. A pesquisa foi realizada de forma exploratória e descritiva por meio do método indutivo. Os resultados da pesquisa identificaram que a grande maioria das empresas apresenta uma estratégia ambiental pautada em exigências legais e não utilizam indicadores de performance ambiental e social em seu sistema de gestão. Os atores sociais entrevistados não têm conhecimento da estratégia ambiental das empresas. Os elementos necessários à empresa para contribuir com a sustentabilidade do município foram percebidos de forma diferenciada pelos atores entrevistados.
\end{abstract}

Palavras-chave: estratégia ambiental; desenvolvimento; sustentabilidade.

\section{ABSTRACT}

Social pressures, economic, political, institutional and ethical are demanding significant changes in organizations in their relations with the environment. In this new environment set up requires a proactive attitude of companies towards their conduct environmental and social. In this context, this paper aims at identifying the social and environmental practices in

\footnotetext{
${ }^{1}$ Artigo recebido em 28.12.2012. Revisado por pares em 25.02.2013 (blind review). Reformulado em 28.03.2013. Recomendado para publicação em 28.03.2013 por José Ribamar Marques de Carvalho (Editor Científico). Publicado em 01.04.2013. Organização responsável pelo periódico UACC/UFCG.
}

REUNIR - Revista de Administração, Contabilidade e Sustentabilidade ISSN: 2237-3667 - Vol.3, no 1, Jan./Abr., p. 103-124, 2013. 
BARBOSA, M. de F. N.; RODRIGUES, D. G.; BARBOSA, M. E. Práticas Socioambientais...

companies potentially polluting or using environmental resources in the municipality of Sousa - PB. Specifically aims to: determine possible environmental models and tools (social and environmental practices) used by enterprises, identify environmental strategy adopted by companies and describe the perception of some stakeholders about the environmental practices of the companies and the sustainability of the municipality. The research was conducted in an exploratory and descriptive through the inductive method. The survey results identified that the vast majority of companies presents an environmental strategy guided by legal requirements and do not use performance indicators in environmental and social management system. The social actors interviewed are unaware of corporate environmental strategy. The elements necessary for the company to contribute to the sustainability of the municipality were perceived differently by the actors interviewed.

Keywords: Environmental strategy. Development.Sustainability.

\section{INTRODUÇÃO}

Com a introdução do conceito de desenvolvimento sustentável no cenário internacional e nacional, exige-se da sociedade civil organizada uma postura proativa em relação as questões ambientais. Sendo a empresa um ente potencialmente gerador de impactos ambientais negativos ao meio ambiente, justifica-se de sua parte uma atitude de co-responsabilidade no sentido de mitigar os impactos oriundos da atividade empresarial desenvolvida nos diversos ramos econômicos.

Mudanças ocorreram nas últimas décadas com ganhos para a sociedade, por outro lado, trouxeram prejuízos sociais e ambientais para essa mesma sociedade. Nesse contexto, as empresas e a sociedade têm um valioso papel a desempenhar como indutoras de um crescimento que aliado aos ganhos financeiros, também agregue em sua concepção a proteção da biosfera e a inserção social da população.

Com o desabrochar do desenvolvimento sustentável diversos instrumentos tem sido colocados a disposição da sociedade com o escopo de lidar com a relação homem-natureza. Conforme Seiffert (2007) existem os instrumentos de gestão ambienal como o princípio do poluidor pagador; os instrumentos de abrangência macro e esfera pública como os pactos internacionais, a agenda 21 e a Política Nacional do Meio Ambiente; os instrumentos de abrangênica micro e esfera pública como o licenciamento ambiental e a Avaliação de Impactos Ambientais; os instrumentos de abrangência micro e esfera privada como a Produção Mais Limpa, os Sistemas de Gestão Ambiental, as Tecnologias Limpas; os instrumentos econômicos de gestão ambiental e a Educação Ambiental, considerada pela autora como o instrumento dos instrumentos. A observância pela empresa de instrumentos de gestão ambiental de forma integrada poderá contribuir para uma boa govenança com os atores sociais locais, com implicações positivas para o desenvolvimento local sustentável.

Não obstante a importância de todos esses instrumentos, cabe destacar o papel que cabe aos empresários no sentido de introduzir, conforme nos sugere Nascimento, Lemos e Mello (2008), um modelo de Responsabilidade Socioambiental em suas estratégias de negócio como forma de contribuir, de um lado, com o desenvolvimento econômico, por outro lado, promover a qualidade de vida de 
BARBOSA, M. de F. N.; RODRIGUES, D. G.; BARBOSA, M. E. Práticas Socioambientais...

empregados e seus familiares, da comunidade local, e por extensão, da sociedade como um todo.

Partindo-se do pressuposto que uma gestão socioambiental por parte das empresas pode contribuir para um desenvolvimento local sustentável, pergunta-se: quais as possíveis relações entre as práticas socioambientais das empresas potencialmente poluidoras no município de Sousa-PB e o desenvolvimento local sustentável? Para responder a este problema de pesquisa tem-se como objetivo geral: identificar as práticas socioambientais em empresas potencialmente poluidoras ou utilizadoras de recursos ambientais no município de Sousa - PB. De forma específica pretende-se: verificar as possíveis ferramentas e modelos ambientais (práticas socioambientais) utilizados pelas empresas; Identificar a estratégia ambiental adotada pelas empresas; descrever a percepção de alguns stakeholders acerca das práticas socioambientais das empresas e da sustentabilidade do município.

\section{FUNDAMENTAÇÃO TEÓRICA}

Dentre os modelos e ferramentas ambientais que podem contribuir para uma postura ambientalmente responsável por parte dos atores sociais envolvidos com a atividade empresarial e que serão de grande valia para os propósitos deste artigo são: o Sistema de Gestão Ambiental (SGA); a Produção Mais Limpa (P+L); a Ecoeficiência; Auditoria Ambiental; Avaliação de Impacto Ambiental; Marketing Ambiental; Responsabilidade Social Corporativa e a Educação Ambiental. Segue considerações acerca dos modelos e ferramentas ambientais que darão suporte a este artigo. Posteriormente será feita uma breve exposição dos temas desenvolvimento sustentável e desenvolvimento local sustentável.

\subsection{Contextualizando os modelos e ferramentas ambientais}

A definição da Associação Brasileira de Normas Técnicas acerca do sistema de gestão ambiental é que o mesmo pode ser definido como "a parte de um sistema da gestão de uma organização utilizada para desenvolver e implementar sua política ambiental e para gerenciar seus aspectos ambientais" (NBR ISO 14001, ABNT, 2004, p. 2).

Conforme Epelbaum (2006), este conceito avança em relação ao conceito adotado pela abordagem tradicional da gestão ambiental por permitir que a empresa operacionalize seus processos ambientais de maneira ordenada e integrada à gestão empresarial, o que antes se realizava com prioridade para o aspecto tecnológico.

De acordo com Barbieri (2007), o SGA representa um conjunto de atividades administrativas e operacionais atuando de modo integrado no sentido de enfrentar os problemas ambientais atuais ou para impedir o seu aparecimento. 
BARBOSA, M. de F. N.; RODRIGUES, D. G.; BARBOSA, M. E. Práticas Socioambientais...

A Produção mais Limpa representa um modelo de produção que se encontra em atuação a partir da década de 80 e seu desenvolvimento deve-se ao Programa das Nações Unidas para o Meio Ambiente (PNUMA) e a Organização das Nações Unidas para o Desenvolvimento Industrial (UNIDO), tendo como escopo maior colocar em prática as ideias inerentes ao desenvolvimento sustentável, dessa forma procura dar respostas ao sistema econômico mundial que ora vivenciamos.

A United National Industrial Development Organization - UNIDO (2004) define a Produção Mais Limpa como uma estratégia preventiva e integrada presente em todas as fases do processo produtivo, com os seguintes objetivos: aumentar a produtividade por meio do uso racional dos materiais, água e energia; melhorar o desempenho ambiental com a redução de resíduos e emissões; redução do impacto ambiental dos produtos em todo o seu ciclo de vida, ancorado a um projeto eficiente nas vertentes ecológica e econômica.

Gasi e Ferreira (2006) consideram que a P + L assim como outros conceitos que levam em consideração em sua estrutura um caráter preventivo são apropriados a darem respostas convincentes sobre como aumentar a capacidade suporte do planeta quando são produzidos bens e serviços. É por esse motivo que esse modelo de gestão ambiental contribui para a qualidade de vida das futuras gerações ao buscar o equilíbrio entre interesses ambientais e econômicos.

Para a OCDE e a WBCSD a ecoeficiência é atingida quando se coloca a disposição da sociedade produtos e serviços dotados de preços competitivos capazes de atenderem as necessidades humanas trazendo ganhos para a qualidade de vida, ao tempo em que diminuem de forma contínua, impactos ambientais negativos e o uso dos recursos considerando-se todo o ciclo de vida desses bens e serviços, todo esse esforço com o escopo maior de se conservar a capacidade suporte do Planeta (ORGANISATION FOR ECONOMIC CO-OPERATION AND DEVELOPMENT, In: BARBIERI, 2007).

Conforme Philippi Jr. e Aguiar (2005), as auditorias ambientais surgiram para dar suporte as empresas multinacionais acerca das condutas ambientais praticadas por suas filiais como forma de se evitar impactos maiores ao meio ambiente e de forma especial a imagem dessas empresas.

Algumas vantagens se observam quando do uso das auditorias: identificação e registro das conformidades e das não-conformidades com a legislação, com regulamentações e normas e com a política ambiental da empresa (caso exista); prevenção de acidentes ambientais; melhor imagem da empresa junto ao público, á comunidade e ao setor público; assessoramento aos gestores na implementação da qualidade ambiental na empresa; avaliação, controle e redução do impacto ambiental da atividade; minimização dos resíduos gerados e dos recursos usados pela empresa. Também são percebidas desvantagens como: mitigar a possibilidade de ocorrer um acidente ambiental e da empresa não atender aos requisitos legais de proteção ambiental; deve ser aplicado com frequência regular (mínima anual), estar inserida 
BARBOSA, M. de F. N.; RODRIGUES, D. G.; BARBOSA, M. E. Práticas Socioambientais...

em um programa de gestão ambiental da empresa e ter garantida a implementação, por parte da empresa, das medidas corretivas das não-conformidades identificadas (LA ROVERE,2001).

Para o Programa das Nações Unidas para o Meio Ambiente (PNUMA) a Avaliação de Impactos Ambientais representa "identificar, predizer e descrever, em termos apropriados, os prós e os contras (danos e benefícios) de uma proposta de desenvolvimento".

Silva (2004) alerta para o fato de que a AIA foi prevista por essas legislações sem que o prazo para sua realização fosse determinado, gerando ineficácia. Entretanto a Constituição Federal de 1988 fixa que a sua realização se antecipe a implementação de uma obra ou atividade, ou seja, seja realizada previamente, essa mudança contribui para o objetivo que motivou sua criação entre nós, qual seja: preservar a melhoria do meio ambiente.

Para Sánchez (2006) a importância da AIA está diretamente ligada ao fato da mesma poder ser incorporada a gestão ambiental em todas as fases do ciclo de vida do negócio, do contrário, o seu poder de instrumento contributivo a uma gestão voltada as questões ambientais fica efetivamente comprometida.

Voltolini (2006) sugere que o conceito de marketing ambiental tem por escopo colocar nos mercados produtos e serviços ecologicamente responsáveis no sentido de atender necessidades e desejos dos consumidores. Ainda chama a atenção para o fato de que, embora o conceito de valor não se encontre explícito no enunciado, o mesmo pode ser percebido quando são observadas mudanças de comportamento dos consumidores quando se decidem por produtos e serviços que tragam o menor impacto ambiental negativo em relação ao meio ambiente.

Para Dias (2007) o marketing ambiental poderia se consubstanciar por meio das seguintes funções: informativa acerca do conteúdo ambiental; educativa vinculada ao processo de informação da empresa, incentivo a posturas que contribuam ao bemestar do meio ambiente.

Vários modelos foram criados com o escopo de delimitar a Responsabilidade Social Corporativa. Esses modelos, por meio dos parâmetros estabelecidos por cada autor, tratam de moldar o comportamento da organização com o propósito de averiguar as etapas de desenvolvimento apresentadas pela mesma.

O modelo de responsabilidade social de Quazi e O'Brien (2000), observando as atividades que a empresa desenvolve, sugere a existência de uma responsabilidade ampla ou restrita. Existe responsabilidade ampla quando a empresa aglutina atividades que vão além das responsabilidades clássicas e econômicas; a responsabilidade restrita, por sua vez, confere a empresa como função primordial a maximização do lucro para os acionistas.

O modelo de RSC de Enderle e Tavis (1998), partindo das dimensões econômica, social e ambiental, agrega em três níveis éticos as responsabilidades corporativas. Por sua vez, Wood (1991), observa nove indicadores considerados por ele comuns a todas 
BARBOSA, M. de F. N.; RODRIGUES, D. G.; BARBOSA, M. E. Práticas Socioambientais...

as empresas, tais indicadores se distribuem nas dimensões: princípios de responsabilidade social (legitimidade, responsabilidade pública e arbítrio dos executivos); processos de capacidade de resposta social (percepção do ambiente, gestão dos stakeholders e de problemas); resultados das ações de responsabilidade social (institucionais e nos stakeholders internos e externos).

O modelo de Carroll (1999) afirma que o conceito de responsabilidade social comporta o mesmo sentido que se observava no passado, apenas sofrendo modificações os problemas com que as empresas se defrontam na atualidade, bem como as ações de responsabilidade social. Dessa forma, propõe um modelo onde evidencia que a RSC pode ser entendida considerando-se quatro dimensões: econômica, ética, legal e discricionária. Assim, esse modelo mostra que uma empresa alcança uma postura socialmente responsável quando essas quatro dimensões são observadas no gerenciamento de suas atividades.

Borger (2006) toma como referência autores como Carroll (1999), Frederick , Wartick e Crochan (1996), Donaldson e Preston no sentido de mostrar os modelos de responsabilidade social que foram se aprimorando para dar respostas às dúvidas surgidas no mundo empresarial em relação a como colocar em prática a gestão da Responsabilidade Social Empresarial (SER). Assim, dentre os modelos referenciados pela autora cabe destacar o modelo do stakeholder, que se fundamenta numa perspectiva sistêmica da organização na sociedade.

Segundo Simons (2006) a educação ambiental deve ser vista como um dos instrumentos imprescindíveis para a gestão ambiental na iniciativa privada empresarial. Dessa forma, os programas de educação ambiental nas empresas não devem evidentemente restringir-se apenas a eventos pontuais, bem como a iniciativas desenvolvidas considerando-se um público externo ou simplesmente para cumprir os ditames contidos na Norma ISO 14001. Deve, pois, ser observada em sua plenitude transformadora, ou seja, sensibilizando e promovendo sentidos de coresponsabilidade ao permitir que os atores participantes do processo compreendam a íntima relação existente entre a qualidade de vida e as práticas sustentáveis dentro e fora dos muros das empresas.

De acordo com Jacobi (2003) a função transformadora a qual cabe a educação ambiental por meio da co-responsabilidade dos indivíduos é que contribui para um novo tipo de desenvolvimento, qual seja: o desenvolvimento sustentável, temática a ser abordada no item a seguir.

\subsection{Desenvolvimento Sustentável e Desenvolvimento Local Sustentável}

É importante discorrer sobre a natureza do Desenvolvimento Sustentável. Alguns o consideram utópico; outros vislumbram como uma teoria, por meio da qual se alcançará metas futuras; há ainda os que explicam sua gênese por intermédio de um 
BARBOSA, M. de F. N.; RODRIGUES, D. G.; BARBOSA, M. E. Práticas Socioambientais...

conjunto de princípios, porém, existem aqueles que o compreendem como um processo.

O conceito de desenvolvimento sustentável é definido pelo Relatório Brundtland (1987) como aquele que provê as necessidades do presente sem comprometer a capacidade das futuras gerações de prover suas próprias necessidades.

O International Council for Local Environmental Initiatives - ICLEI (Conselho Internacional para Iniciativas Ambientais Locais) (1994), diz que o Desenvolvimento Sustentável proporciona serviços básicos da ordem ambiental, social e econômica a todos os residentes da comunidade, sem ameaçar a viabilidade dos sistemas naturais, construídos e sociais dos quais estes serviços dependem.

Conforme o UK Departament of Environmental, Transport and Regions (Departamento do Meio Ambiente, de Transporte e das Regiões do Reino Unido) (1999), o Desenvolvimento Sustentável deve reconhecer as necessidades de todos, a proteção efetiva do meio ambiente, o uso prudente dos recursos naturais, a manutenção de um crescimento econômico e do emprego estável.

Costanza (1991) acredita que o conceito de desenvolvimento sustentável deve estar inserido na relação dinâmica entre o sistema econômico e o ecológico. Dahl (1997) sua vez, chama a atenção para o fato de que o conceito de desenvolvimento sustentável comporta valores, dessa forma dará margens a diversas interpretações sobre o seu real significado. Por conseguinte, este conceito ganha novo impulso com o alargamento do entendimento dado por Sachs (1997) ao agregar cinco dimensões da sustentabilidade em seus princípios: social, econômica, ecológica, geográfica e cultural.

Por sua vez, o desenvolvimento local sustentável representa um processo endógeno, propulsor do desenvolvimento econômico e da melhoria da qualidade de vida da população, sendo o resultado da mobilização da sociedade, capaz de explorar suas potencialidades intrínsecas e alavancar oportunidades sociais, viabilidade e competitividade da economia local, ao tempo em que se gera renda e conservação dos recursos naturais (BUARQUE, 1999).

\section{PROCEDIMENTOS METODOLÓGICOS}

O método de abordagem implica um conjunto de procedimentos adotados na investigação de fenômenos ou no caminho para chegar-se à verdade. (CERVO; BERVIAN, 1983). Os métodos de abordagem preocupam-se com o plano geral do trabalho, seus fundamentos lógicos e ao processo de raciocínio adotado. Nessa pesquisa foi adotado o raciocínio indutivo, uma vez que parte da compreensão das relações entre as práticas socioambientais das empresas com o desenvolvimento local sustentável, ou seja, de uma perspectiva particular, as práticas socioambientais da empresa, para uma perspectiva maior, as implicações dessas práticas no desenvolvimento local. 
BARBOSA, M. de F. N.; RODRIGUES, D. G.; BARBOSA, M. E. Práticas Socioambientais...

Quanto aos fins: foi uma pesquisa exploratória e descritiva. Exploratória, no sentido de não existir conhecimento sistematizado sobre as práticas socioambientais das empresas potencialmente poluidoras no município de Sousa/PB; descritiva, uma vez que expos as características das empresas pesquisadas. Quanto aos meios: tratase de uma pesquisa bibliográfica, documental e de campo. (VERGARA, 1997)

Os instrumentos técnicos utilizados na coleta de dados foram os seguintes: observação, formulário e entrevista semi-estruturada.

A observação utilizada enfocou aspectos qualitativos e quantitativos do objeto de estudo analisado. O formulário é uma técnica de pesquisa utilizada cuja coleta de dados tem o propósito de obter informações diretamente do entrevistado. Quanto à utilização da entrevista semi-estruturada, foi de grande valia, pois, permite ao pesquisador um amplo relacionamento com o informante, além de possibilidade de re-orientação ou retro-alimentação dessa técnica de pesquisa.

O tratamento dos dados dessa pesquisa foi realizado através de um método misto, ou seja, se utilizou de técnica quantitativa e qualitativa numa proporção que contribuiu para obter esclarecimentos consistentes e complementares acerca da problemática que se pretende investigar.

Os sujeitos da pesquisa, ou seja, as pessoas que contribuíram com informações para o desenvolvimento dessa pesquisa foram os donos das indústrias dos setores de laticínio, doce, sabão, café e detergente. Foi ainda entrevistado um representante do poder público do município e entidades de apoio dos setores pesquisados.

$\mathrm{O}$ universo da pesquisa foram as indústrias potencialmente poluidoras ou utilizadoras de recursos ambientais, quais sejam: indústrias de sabão; laticínios; doce; café e indústria de detergente, ou seja, um universo de 11 empresas. Entretanto, a amostra se realizou por acessibilidade e foram entrevistadas 9 empresas, assim distribuídas: 3 de sabão; 1 de café; 1 de doce; 1 de detergente e 3 de laticínios.

O quadro 1 apresenta de forma simplificada as dimensões, variáveis e critérios que foram adotados para análise das práticas socioambientais das empresas.

\begin{tabular}{|c|c|c|}
\hline DIMENSÕES & VARIÁVEIS & CRITÉRIOS \\
\hline $\begin{array}{l}\text { Sistema de } \text { Gestão } \\
\text { Ambiental }\end{array}$ & $\begin{array}{l}\text { Política Ambiental } \\
\text { - Existência de uma } \\
\text { política ambiental } \\
\text { escrita }\end{array}$ & $\begin{array}{l}\text { A variável é avaliada } \\
\text { positivamente quando da } \\
\text { existência de uma política } \\
\text { ambiental escrita. }\end{array}$ \\
\hline o Mais Limpa & \begin{tabular}{rll}
\multicolumn{2}{l}{ Conservação de matérias-primas } \\
e energia & & \\
$\bullet$ & Existência & de \\
& mecanismos & de \\
& conservação & de \\
& água e energia & \\
\end{tabular} & $\begin{array}{l}\text { A variável é avaliada } \\
\text { positivamente quando da } \\
\text { existência de algum } \\
\text { mecanismo de conservação } \\
\text { de água e energia. }\end{array}$ \\
\hline Ecoeficiência & $\begin{aligned} & \text { Controle da Poluição } \\
& \bullet \quad \text { Existência } \\
& \text { mecanismos } \\
&\end{aligned}$ & $\begin{array}{l}\text { A variável é avaliada } \\
\text { positivamente quando da } \\
\text { existência de alguma forma }\end{array}$ \\
\hline
\end{tabular}

REUNIR - Revista de Administração, Contabilidade e Sustentabilidade

ISSN: 2237-3667 - Vol.3, nº 1, Jan./Abr., p. 103-124, 2013. 
BARBOSA, M. de F. N.; RODRIGUES, D. G.; BARBOSA, M. E. Práticas Socioambientais...

\begin{tabular}{|c|c|c|}
\hline & controlar a poluição & de controle da poluição. \\
\hline Auditoria Ambiental & $\begin{array}{ll}\text { Número } & \text { de auditorias } \\
\text { ambientais internas realizadas } \\
\bullet & \text { Existência de } \\
& \text { auditorias } \\
& \text { ambientais internas } \\
& \text { realizadas }\end{array}$ & $\begin{array}{l}\text { A variável é avaliada } \\
\text { positivamente quando da } \\
\text { realização de pelo menos } \\
\text { uma auditoria ambiental } \\
\text { interna por ano. }\end{array}$ \\
\hline $\begin{array}{l}\text { Avaliação de Impacto } \\
\text { Ambiental }\end{array}$ & 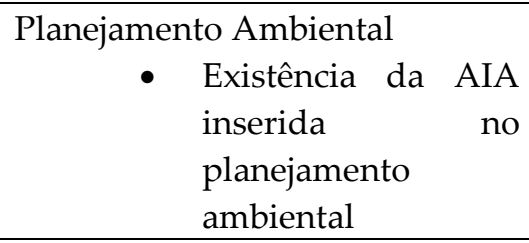 & $\begin{array}{l}\text { A variável é avaliada } \\
\text { positivamente quando a AIA } \\
\text { fizer parte do planejamento } \\
\text { ambiental da empresa }\end{array}$ \\
\hline Mar & \begin{tabular}{lll}
\multicolumn{2}{l}{ Informações ambientais } & \\
$\bullet$ & $\begin{array}{l}\text { Divulgação } \\
\text { informações }\end{array}$ & de \\
& ambientais & aos \\
& consumidores &
\end{tabular} & $\begin{array}{l}\text { A variável é avaliada } \\
\text { positivamente } \\
\text { divulgação de } \\
\text { ambientais informações } \\
\text { interessadas. }\end{array}$ \\
\hline $\begin{array}{l}\text { Responsabilidade Social } \\
\text { Corporativa }\end{array}$ & $\begin{array}{l}\text { Política de responsabilidade } \\
\text { social corporativa } \\
\qquad \begin{array}{ll}\text { Existência de uma } \\
& \text { política de } \\
& \text { responsabilidade } \\
& \text { social corporativa } \\
\end{array}\end{array}$ & $\begin{array}{l}\text { A variável é avaliada } \\
\text { positivamente quando da } \\
\text { existência de uma política de } \\
\text { responsabilidade social } \\
\text { corporativa. }\end{array}$ \\
\hline Educação Ambiental & 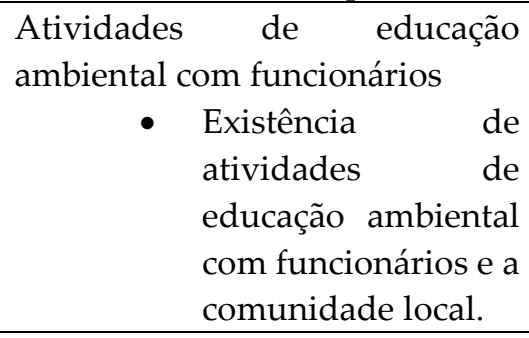 & $\begin{array}{llr}\text { A variável é } & \text { avaliada } \\
\text { positivamente } & \text { quando da } \\
\text { existência de } & \text { alguma } \\
\text { atividade de } & \text { educação } \\
\text { ambiental com r os } \\
\text { funcionários e a comunidade } \\
\text { local }\end{array}$ \\
\hline $\begin{array}{l}\text { Performance Ambiental e } \\
\text { Social }\end{array}$ & 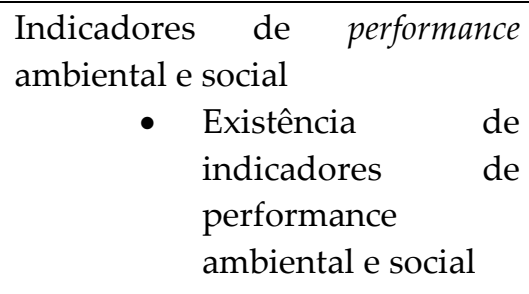 & $\begin{array}{l}\text { A variável é avaliada } \\
\text { positivamente quando da } \\
\text { existência de indicadores de } \\
\text { performance ambiental e social } \\
\text { por mais de } 70 \% \text { das } \\
\text { empresas. }\end{array}$ \\
\hline
\end{tabular}

Quadro 1: Dimensões, variáveis e critérios de análise das práticas socioambientais

Fonte: Elaboração Própria (2011)

A estratégia ambiental foi apreendida por meio da compreensão das práticas socioambientais apresentadas pelas empresas pesquisadas. $\mathrm{O}$ desenvolvimento local sustentável nessa pesquisa foi observado por meio de dados primários e secundários. Os dados primários foram obtidos por meio de pesquisa com os atores locais conforme anexo 1 da pesquisa de Souza (2011). Os dados secundários foram obtidos por meio do estudo desenvolvido por Martins e Cândido (2008) que leva em consideração as seguintes dimensões: econômica, social, ambiental, político- 
BARBOSA, M. de F. N.; RODRIGUES, D. G.; BARBOSA, M. E. Práticas Socioambientais...

institucional, demográfica e cultural, para a análise do nível de sustentabilidade de municípios.

\section{APRESENTAÇÃO E DISCUSSÃO DOS RESULTADOS}

\subsection{Parte I: Conduta e Desempenho Ambiental}

A maioria das empresas (8) afirmaram não possuir uma política ambiental escrita. Dessas 8, 1 disse que trabalha a questão ambiental na empresa apenas de forma verbal, no dia a dia da empresa. A única empresa que afirmou ter uma política ambiental escrita, disse que os compromissos assumidos na política ambiental eram: controle da radiação; da água; do ar e dos resíduos.

Das 9 empresas pesquisadas, 7 responderam que não estão implementando um Sistema de Gestão Ambiental (SGA), entretanto, essas empresas tem pretensão de implantá-lo em seu sistema de negócios. Apenas 1 empresa está certificada pela ISO 14001, sendo que os motivos que a fizeram adotar o SGA foram: acidentes ambientais na empresa; atendimento à legislação e preocupação com a imagem da empresa no mercado. Das 7 que disseram não estar implantando um SGA, os motivos para não adotar foram parecidos, a exemplo de não sofrer pressão da legislação ambiental (3 empresas); não conhecer o funcionamento de um gerenciamento ambiental (4 empresas) e acreditar que a atividade produtiva na qual atuam não gerar impactos sobre o meio ambiente (3 empresas). Para a empresa que já implantou um SGA os benefícios mais perceptíveis são melhoria da imagem; redução de custo e melhoria da comunicação interna.

Como a maioria das empresas não têm uma política ambiental escrita, esta variável será avaliada de forma negativa, conforme parâmetros adotados na pesquisa.

Das 9 empresas pesquisadas, 6 disseram não adotar nenhuma política de responsabilidade social. Das 3 empresas que adotam alguma política, a mesma encontra-se atrelada a projetos sociais, destacando-se a empresa 3 que observa um manual de boas práticas.

Conforme critério adotado, a dimensão responsabilidade social corporativa será avaliada de forma negativa.

Das 9 empresas pesquisadas, 5 se pronunciaram acerca do consumo anual de água. No que se refere à adoção de algum mecanismo de conservação de água, 6 empresas responderam positivamente e em situações diversas. Apenas 4 empresas se pronunciaram em relação ao consumo anual de energia e apenas 5 adotam algum mecanismo de conservação de energia.

A variável será avaliada de forma positiva, pois $67 \%$ das empresas adotam algum mecanismo de conservação de água e 56\% adotam algum mecanismo de conservação de energia. 
BARBOSA, M. de F. N.; RODRIGUES, D. G.; BARBOSA, M. E. Práticas Socioambientais...

Das 9 empresas entrevistadas 7 adotam algum mecanismo de prevenção e controle da poluição, tais como: filtros nas chaminés; incinerar plástico; vistorias; estação de tratamento e coleta seletiva.

A variável será avaliada de forma positiva, pois 78\% das empresas adotam algum mecanismo de prevenção e controle da poluição.

Quanto ao questionamento se a empresa avalia os impactos ambientais relativos à sua atividade, produtos e serviços 8 empresas disseram que fazem essa avaliação. Dessas 8, 6 disseram que realizaram apenas durante a implantação da fábrica com o Estudo de Impacto Ambiental e 2 disseram que fazem continuamente através do levantamento dos aspectos e impactos ambientais significativos.

A variável será avaliada de forma negativa, pois a AIA, na maioria das empresas não fazem parte do seu planejamento ambiental.

Das 9 empresas entrevistadas, 5 disseram que fazem auditoria ambiental interna. Dessas cinco, 2 empresas realizam 2 auditorias por ano, as outras realizam apenas 1 auditoria.

Durante a realização das entrevistas 6 empresas disseram que nenhuma auditoria ambiental interna estava atuando na empresa e 2 empresas estavam sendo fiscalizadas. A empresa 3 estava sendo fiscalizada pela ANVISA; ANGEVISA E Ministério do Trabalho e a empresa 4 pela Vigilância Sanitária e pelo IBAMA.

A variável será avaliada de forma positiva, pois $56 \%$ das empresas pesquisadas fazem pelo menos uma auditoria interna por ano.

No que tange as principais exigências ambientais dos clientes, 6 empresas responderam que os clientes não tem exigências ambientais. Para as três restantes, 2 empresas disseram que as exigências ambientais representam normas dos próprios clientes. Quanto a outra empresa, além de normas dos próprios clientes, ainda levam em consideração o selo verde e a NBR ISO 14001.

Das 9 empresas entrevistadas, 7 responderam não produzir relatórios de desempenho ambiental. Para as 2 que responderam que produzem, uma disse que produz apenas para conhecimento restrito das gerências, quanto a outra, disse que produz para o ministério da agricultura. As 2 empresas não se pronunciaram quanto a frequência dos relatórios produzidos.

Os motivos que levam as empresas a não adotarem relatórios de desempenho ambiental foram: 2 das empresas ( 5 e 8) não acreditam na necessidade de elaborar relatórios de desempenho ambiental; outras 3 empresas $(2,4$ e 9) disseram que nunca foi exigido esse tipo de relatório. A empresa 1 disse não dispor de pessoal treinado para elaborar esses relatórios. A empresa 6 disse que a ANVISA notifica.

Seis empresas disseram adotar alguma preocupação para gerenciar os riscos ambientais na distribuição de seus produtos, conforme especificidades de cada produto. 
BARBOSA, M. de F. N.; RODRIGUES, D. G.; BARBOSA, M. E. Práticas Socioambientais...

A variável será avaliada de forma negativa, pois 78\% \% das empresas pesquisadas não divulgam informações ambientais as partes interessadas por meio de relatórios de desempenho ambiental.

Das 9 empresas entrevistadas, 7 disseram não possuir um programa de educação ambiental; 2 empresas disseram adotar um programa de educação ambiental através do programa $3 \mathrm{R}$ (reciclar - reusar - reutilizar), enquanto a empresa 9 disse possuir um programa de educação ambiental por meio de palestras.

Das 9 empresas entrevistas, 7 não promovem atividades de educação ambiental com a comunidade. Para as duas empresas que desenvolvem esta atividade, as ações se traduzem no recebimento de embalagens para reciclar e preocupação com a qualidade dos produtos (empresa 4) e na doação de materiais recicláveis para a comunidade (empresa 8).

A variável será avaliada de forma negativa, pois $78 \% \%$ das empresas pesquisadas não promovem atividades de educação ambiental com a comunidade local, nem com os funcionários.

Das 9 empresas entrevistadas, 5 estabelecem indicadores de desempenho ambiental, principalmente através dos padrões legais. As áreas que as empresas estabeleceram indicadores de desempenho ambiental, por ordem de prioridade são: água (4 empresas), resíduos sólidos (4 empresas) e efluentes líquidos (3 empresas).

Os motivos que levam as empresas a não adotarem indicadores de desempenho ambiental foi respondido apenas por 2 das empresas, qual seja: nunca foi exigido pelos órgãos de fiscalização o estabelecimento de indicadores de desempenho ambiental.

Para as empresas que adotam indicadores de desempenho ambiental, a sistemática para a melhoria contínua desses indicadores são: por meio de palestras, vídeos (empresa 3); procurar economizar o consumo de lenha através de isolamento térmico e novas tecnologias (empresa 6); projetos de melhoria (empresa 8) e de forma cotidiana em relação a utilização de aparelhos que contribuam para economizar água e energia (empresa 9).

Das 9 empresas entrevistadas, 8 empresas disseram ter contribuído com a geração de emprego na região nos últimos 2 anos. As empresas 1e 2 disseram ter empregado 10 pessoas nesse período; a empresa 3 disse ter empregado $10 \%$ a mais nas áreas de produção e comercial; a empresa 4 disse ter empregado 5 pessoas nesse período; a empresa 5 disse ter gerado oportunidades para as pessoas que nunca trabalharam; a empresa 8 disse ter tido um recorde de admissão e a empresa 9 empregou 50 pessoas.

Quanto aos benefícios extras concedidos aos funcionários, destacam-se: espaço de lazer (empresas 1, 3, 7, 8 e 9); prêmios/bônus (empresas 2, 6, 7 e 8). Vale salientar que nenhuma empresa fez menção ao indicador participação nos resultados da empresa.

A relação da empresa com a comunidade do entorno no que se refere aos benefícios sociais foi considerada boa por todas as empresas entrevistadas. 
BARBOSA, M. de F. N.; RODRIGUES, D. G.; BARBOSA, M. E. Práticas Socioambientais...

A variável será avaliada de forma negativa, pois apenas $56 \%$ das empresas pesquisadas estabelecem indicadores de desempenho ambiental e nenhuma empresa estabelece indicadores para a dimensão social.

O quadro 2 apresenta de forma sistematizada os resultados obtidos para a conduta e performance ambiental e social das empresas pesquisadas.

\begin{tabular}{|l|l|}
\hline DIMENSÕES DA CONDUTA & AVALIAÇÃO \\
\hline Sistema de Gestão Ambiental & Negativa \\
\hline Responsabilidade Social Corporativa & Negativa \\
\hline Produção Mais Limpa & Positiva \\
\hline Ecoeficiência & Positiva \\
\hline Avaliação de Impactos Ambientais & Negativa \\
\hline Auditoria Ambiental & Positiva \\
\hline Marketing Ambiental & Negativa \\
\hline Educação Ambiental & Negativa \\
\hline PERFORMANCE AMBIENTAL E SOCIAL & AVALIAÇÃO \\
\hline Indicadores de performance ambiental e social & Negativa \\
\hline
\end{tabular}

Quadro 2: Conduta e performance ambiental e social das empresas

Fonte: Pesquisa de Campo (2011)

\subsection{Parte II: Análise da Percepção dos Stakeholders acerca das Ações da Empresa em relação à Gestão Ambiental e Sustentabilidade do Município}

\section{A) Secretaria de Desenvolvimento do Município}

O município, sob a perspectiva da secretaria de desenvolvimento, tem uma visão negativa acerca das questões ambientais das empresas. Entre outros aspectos: não percebe os benefícios diretos ou indiretos para o município das ações de gestão ambiental desenvolvidas pela empresa; não conhece a estratégia ambiental das empresas; não tem conhecimento das ações de gestão ambiental que as empresas deveriam desenvolver para minimizar os impactos ambientais no município.

No tocante aos elementos necessários à empresa para contribuir com a sustentabilidade de um município, a secretaria de desenvolvimento afirmou que seria a geração de emprego. 
BARBOSA, M. de F. N.; RODRIGUES, D. G.; BARBOSA, M. E. Práticas Socioambientais...

Quanto ao grau de importância dados aos indicadores da dimensão cultural, destacaram-se: existência de bibliotecas públicas; existência de centros culturais e existência de unidades de ensino superior.

No que tange ao grau de importância dado aos indicadores da dimensão demográfica destacou-se como muito importante apenas a taxa de crescimento da população. Densidade demográfica; razão de dependência da população; taxa de fecundidade e razão entre população urbana/rural foram consideradas importante e a razão entre população masculina/feminina foi considerada pouco importante.

Na dimensão social destacam-se como muito importante os indicadores: índice de gini da distribuição do rendimento; rendimento familiar per capita; esperança de vida ao nascer; oferta de serviços básicos de saúde; taxa de mortalidade infantil; prevalência de desnutrição total; taxa de escolarização; taxa de alfabetização; analfabetismo funcional e adequação de moradia.

$\mathrm{Na}$ dimensão institucional, destacaram-se os seguintes indicadores como muito importante: acesso a serviços básicos da justiça e comparecimento nas eleições. Foram considerados pouco importante o acesso público a internet e as transferências intergovernamentais da união.

Quanto à dimensão ambiental, foram considerados os seguintes indicadores como muito importante: acesso a esgotamento sanitário (urbano); acesso a abastecimento de água (urbano); qualidade das águas saneadas (urbano) e pastagens e lavouras.

$\mathrm{Na}$ dimensão econômica foi dada ênfase aos indicadores: participação da agropecuária no PIB e participação da administração pública no PIB.

\section{B) SEBRAE}

A visão do SEBRAE sobre as questões ambientais da empresa são mais de proatividade do que de reatividade. Entende que as empresas tem uma importante missão a desempenhar frente à sustentabilidade do município. No que tange aos benefícios diretos ou indiretos para o município das ações de gestão ambiental desenvolvidas pela empresa, estes estão diretamente ligados à própria imagem da empresa.

Quanto aos elementos necessários à empresa para contribuir com a sustentabilidade de um município destacou: não poluir e desenvolver ações de responsabilidade social empresarial.

Quanto ao grau de importância aos indicadores da dimensão cultural destacaram-se: existência de bibliotecas públicas; existência de centros culturais; existência de unidades de ensino superior e existência de teatros ou salas de espetáculos.

No que tange ao grau de importância aos indicadores da dimensão demográfica foram considerados: razão de dependência da população; taxa de crescimento da população e taxa de fecundidade. 
Na dimensão social, os indicadores considerados muito importante foram: índice de gini da distribuição do rendimento; rendimento familiar per capita; famílias atendidas por transferências de benefícios sociais; oferta de serviços básicos de saúde; taxa de mortalidade infantil; prevalência de desnutrição total; taxa de escolarização; taxa de alfabetização; analfabetismo funcional; mortalidade por homicídio e adequação de moradia.

Na dimensão institucional, foram considerados muito importantes os indicadores: acesso a serviços de telefonia; acesso a serviços básicos da justiça; transferências intergovernamentais da união e funcionamento dos conselhos municipais.

Os indicadores muito importantes da dimensão ambiental foram: acesso a esgotamento sanitário (urbano); acesso a serviço de coleta de lixo doméstico (urbano); acesso a sistema de abastecimento de água (urbano); qualidade das águas saneadas (urbano) e matas e florestas.

No que se refere aos indicadores da dimensão econômica, destacaram-se como muito importante: participação da indústria no PIB; participação da agropecuária no PIB e renda proveniente de trabalho.

\section{C) SESI}

A visão do SESI sobre a percepção que ele tem das empresas em relação às questões ambientais se mostrou positiva. A forma de cooperação entre o SESI e as empresas se efetiva por meio de prêmios, levando em consideração principalmente a qualidade. Entretanto, o mesmo não conhece a estratégia ambiental utilizada pelas empresas.

No que se refere aos elementos necessários à empresa para contribuir com a sustentabilidade de um município o mesmo chamou a atenção para os serviços sociais, ambientais e cidadania.

Quanto ao grau de importância aos indicadores da dimensão cultural, o SESI considerou como de grau muito importante: existência de bibliotecas públicas; existência de museus; existência de centros culturais; existência de unidades de ensino superior e existência de ginásios de esportes e estádios.

Nenhum indicador da dimensão demográfica foi considerado como muito importante a ser observado pelo município para contribuir com a sua sustentabilidade.

No tocante aos indicadores da dimensão social, foram considerados como muito importante: razão entre rendimento masculino/feminino; oferta de serviços básicos de saúde; imunização contra doenças infecciosas infantis; taxa de escolarização e taxa de alfabetização.

Considerando-se os indicadores da dimensão institucional foram considerados como muito importante: acesso público a internet; acesso de serviços de telefonia; 
BARBOSA, M. de F. N.; RODRIGUES, D. G.; BARBOSA, M. E. Práticas Socioambientais...

acesso a serviços básicos da justiça; comparecimento nas eleições e despesas por função (cultura, urbanismo, gestão ambiental; C\&T, desporto e lazer).

No que tange aos indicadores da dimensão ambiental, os que se destacaram como muito importante foram: acesso a esgotamento sanitário (urbano); acesso a serviço de coleta de lixo doméstico (urbano); acesso a sistema de abastecimento de água (urbano); consumo médio per capita de água e volume da água tratada (para consumo humano). Todos os indicadores da dimensão econômica foram considerados como muito importante para o SESI.

Confrontando-se os indicadores considerados muito importantes pelos atores sociais a serem observados para a sustentabilidade do município, foram observados os resultados a seguir:

Na dimensão cultural, a secretaria de desenvolvimento do município, o SEBRAE e o SESI consideraram os indicadores: existência de bibliotecas públicas; existência de centros culturais e existência de unidades de ensino superior com um grau de importância muito grande a ser observado pelo município. Além destes, o SEBRAE ainda considerou que a existência de teatros ou salas de espetáculos deveria ser considerada também como muito importante e o SESI ainda considerou muito importante os indicadores existência de museus e existência de ginásios de esportes e estádios.

No que concerne à dimensão demográfica o indicador taxa de crescimento da população foi considerado como muito importante pela secretaria de desenvolvimento do município e pelo SEBRAE. O SEBRAE ainda considerou como muito importante os indicadores: razão de dependência da população e taxa de fecundidade. O SESI, por sua vez, não considerou como muito importante nenhum dos indicadores da dimensão demográfica.

Quanto à dimensão social, os atores entrevistados concordaram que os indicadores: oferta de serviços básicos de saúde; taxa de escolarização e taxa de alfabetização são muito importantes a serem observados pelo município. A secretaria de desenvolvimento do município e o SEBRAE ainda concordaram quanto à importância dos indicadores: índice de gene da distribuição do rendimento; rendimento familiar per capita; taxa de mortalidade infantil; analfabetismo funcional e adequação de moradia. Em contraste aos atores citados anteriormente, o SESI considerou ainda como muito importante a ser considerados para a sustentabilidade do município os indicadores: razão entre rendimento masculino/feminino e imunização contra doenças infecciosas infantis. Vale salientar que o indicador esperança de vida ao nascer foi considerado como muito importante apenas pela secretaria de desenvolvimento do município e os indicadores famílias atendidas por transferência de benefícios sociais e mortalidade por homicídio foi considerada como muito importante apenas pelo SEBRAE.

Na dimensão político - institucional, apenas o indicador acesso a serviços básicos da justiça foi considerado como muito importante pelos atores entrevistados a ser 
BARBOSA, M. de F. N.; RODRIGUES, D. G.; BARBOSA, M. E. Práticas Socioambientais...

observado na sustentabilidade do município. O SEBRAE e o SESI concordaram quanto ao grau de importância do indicador: acesso a serviços de telefonia. $\mathrm{O}$ indicador comparecimento nas eleições foi considerado como muito importante para a secretaria de desenvolvimento do município e para o SESI. Os indicadores transferências intergovernamentais da união e funcionamento dos conselhos municipais foi considerado muito importante apenas pelo SEBRAE enquanto que acesso público a internet e despesas por função foi considerado como muito importante apenas pelo SESI.

No que diz respeito à dimensão ambiental, os indicadores acesso a esgotamento sanitário (urbano) e acesso a sistema de abastecimento de água (urbano) foram considerados como muito importantes por todos os atores entrevistados. Qualidade das águas saneadas (urbano) foi considerada como muito importante pela secretaria de desenvolvimento do município e pelo SEBRAE e acesso a serviço de coleta de lixo doméstico (urbano) foi considerado como muito importante pelo SEBRAE e pelo SESI. Os indicadores pastagens e lavouras foram considerados como muito importante apenas pela secretaria de desenvolvimento do município, enquanto que o indicador matas e florestas foi considerado como muito importante apenas pelo SEBRAE e os indicadores consumo médio per capita de água e volume da água tratada foram considerados como muito importantes apenas pelo SESI.

Por fim, na dimensão econômica, o único indicador considerado como muito importante pelos atores pesquisados foi a participação da agropecuária no PIB. Participação da indústria no PIB foi considerada como muito importante pelo SEBRAE e pelo SESI, enquanto que participação da administração pública no PIB foi considerada como muito importante pela secretaria de desenvolvimento do município e pelo SESI. O indicador renda proveniente de trabalho foi considerado como muito importante apenas pelo SEBRAE e os indicadores participação de comércio/serviço no PIB PIB per capita foram considerados como muito importantes apenas pelo SESI.

O quadro 3 apresenta de forma sistematizada os principais resultados da percepção dos Stakeholders acerca das ações das empresas em relação à Gestão Ambiental e dos elementos necessários à sustentabilidade do município.

\begin{tabular}{|c|c|c|}
\hline $\begin{array}{c}\text { SECRETARIA DE } \\
\text { DESENVOLVIMENTO DO } \\
\text { MUNICÍPIO }\end{array}$ & SEBRAE & SESI \\
\hline $\begin{array}{l}\text { Gestão Ambiental } \\
\qquad \quad \text { Percepção negativa }\end{array}$ & $\begin{array}{l}\text { Gestão Ambiental } \\
\qquad \quad \text { Percepção positiva }\end{array}$ & $\begin{array}{l}\text { Gestão Ambiental } \\
\qquad \quad \text { Percepção positiva }\end{array}$ \\
\hline $\begin{array}{l}\text { Elementos necessários à } \\
\text { sustentabilidade do município } \\
\text { - Geração de }\end{array}$ & $\begin{array}{l}\text { Elementos necessários à } \\
\text { sustentabilidade do município } \\
\text { - Não poluir e }\end{array}$ & $\begin{array}{l}\text { Elementos necessários à } \\
\text { sustentabilidade do município } \\
\bullet \quad \text { Promover serviços } \\
\text { sociais, ambientais }\end{array}$ \\
\hline
\end{tabular}


BARBOSA, M. de F. N.; RODRIGUES, D. G.; BARBOSA, M. E. Práticas Socioambientais...

\begin{tabular}{|l|l|l|}
\hline emprego & desenvolver ações & e cidadania. \\
de & \\
& responsabilidade & \\
social empresarial & \\
& \\
\hline
\end{tabular}

Quadro 3: Percepção dos Stakeholders acerca das ações das empresas em relação à gestão ambiental e dos elementos necessários à sustentabilidade do município.

Fonte: Pesquisa de Campo (2011)

Vale salientar que o nível de sustentabilidade do município de Sousa -PB, conforme dados secundários do estudo desenvolvido por Martins e Cândido (2008), encontra-se num nível de alerta, o que poderá demandar políticas públicas nas dimensões: cultural, demográfica, social, político-institucional; ambiental e econômica.

\section{CONSIDERAÇÕES FINAIS}

Pautando-se na análise dos resultados percebe-se uma postura ambiental frágil das empresas pesquisadas, com seis dimensões negativas e apenas três positivas, o que poderá comprometer as relações dessas empresas com o desenvolvimento local sustentável.

As práticas ambientais das empresas estão mais bem representadas pelas ferramentas ambientais: produção mais limpa; ecoeficiência e auditoria ambiental. As ferramentas ambientais sistema de gestão ambiental; avaliação de impactos ambientais; marketing ambiental e educação ambiental carecem ser incorporadas na estrutura organizacional das empresas.

A performance ambiental das empresas foi avaliada de forma negativa, o que inviabiliza a quantificação e possível mitigação dos impactos ambientais negativos dessas empresas no entorno em que desenvolvem suas atividades. No que tange as práticas sociais, a responsabilidade social corporativa não está sendo incorporada pela maioria das empresas, o que poderá comprometer relações mais transparentes com as partes interessadas mais diretamente ligadas as empresas.

A estratégia ambiental adotada pela maioria das empresas está baseada nas exigências dos órgãos ambientais, pois apenas uma empresa adota uma sistemática de melhoria contínua em seu sistema de negócios.

Os indicadores considerados muito importantes simultaneamente pelos atores sociais a serem observados para a sustentabilidade do município foram: existência de bibliotecas públicas, existência de centros culturais e existência de unidades de ensino superior (dimensão cultural); na dimensão demográfica nenhum indicador foi considerado como muito importante pelos atores entrevistados; oferta de serviços 
BARBOSA, M. de F. N.; RODRIGUES, D. G.; BARBOSA, M. E. Práticas Socioambientais...

básicos de saúde; taxa de escolarização e taxa de alfabetização (dimensão social); apenas o indicador acesso a serviços básicos da justiça foi considerado como muito importante pelos atores entrevistados a ser observado na dimensão institucional; acesso a esgotamento sanitário urbano e acesso a sistema de abastecimento de água urbano (ambiental) e participação da agropecuária no PIB (dimensão econômica).

Os resultados da pesquisa apontam tendências que possam ser observadas pelas empresas e polos atores sociais para o fortalecimento das estratégias ambientais das empresas e o planejamento do desenvolvimento local sustentável. Assim, para os propósitos dessa pesquisa, sugere-se que as empresas implantem sistemas de gestão ambiental que observem a demanda dos principais públicos de interesse na empresa; desenvolvam um sistema de indicadores de performance ambiental que minimize os impactos ambientais de sua atividade no entorno onde está situada; incorporem indicadores sociais em seu sistema de negócios; desenvolvam parcerias com a comunidade local, poder público e instituições de apoio em prol de ações que promovam o desenvolvimento local sustentável.

A contribuição desse estudo está atrelada aos possíveis desdobramentos que possam ser estabelecidos entre as organizações e o desenvolvimento local sustentável. Como limitações apresenta: número reduzido de stakeholders entrevistados; o número de indicadores em cada dimensão da conduta ambiental e social talvez não tenham sido suficientes para se fazer generalizações, por fim, a subjetividade inerente aos critérios adotados para analisar a conduta e performance ambiental e social podem não ser suficientes para abarcar o contexto de outros setores econômicos e outras realidades territoriais. Dessa forma, sugere-se que essa pesquisa seja replicada em outros setores econômicos e outros contextos municipais, com um número maior de stakeholders e de indicadores nas dimensões da conduta e performance ambiental e social.

\section{REFERÊNCIAS}

ASSOCIAÇÃO BRASILEIRA DE NORMAS TÉCNICAS. NBR ISO 14001: Sistemas da gestão ambiental - Requisitos com orientações para uso. Rio de Janeiro, 2004.

BARBIERI, J. C. Gestão ambiental empresarial: conceitos, modelos e instrumentos. São Paulo: Saraiva, 2007.

BORGER, F. G. Responsabilidade corporativa: a dimensão ética, social e ambiental na gestão das organizações. In: VILELA JR., Alcir; DEMAJOROVIC, Jacques.(Org.) Gestão ambiental: desafios e perspectivas para as organizações. São Paulo: Editora Senac, 2006. cap. 1, p. 13 - 40. 
BARBOSA, M. de F. N.; RODRIGUES, D. G.; BARBOSA, M. E. Práticas Socioambientais...

BRUNDTLAND, G. H. World Comission on Environment and Development. Our Common Future. Oxford: Oxford University Press, 1987.

BUARQUE, S. C. Metodologia de planejamento do desenvolvimento local e municipal sustentável. Brasília: INCRA/IICA, 1999.

CARROLL, A. Corporate social responsibility. Business and Society, v. 8, n. 3, p. 268295, 1999.

CERVO, A. L.; BERVIAN, P. A. Metodologia científica. 3. ed. São Paulo: McGrawHill do Brasil, 1983.

COSTANZA, R. Ecological economics: the science and management of sustainability. New York: Columbia Press, 1991.

DAHL, A. L. The big picture: comprehensive approaches. In: MOLDAN, B. BILHARZ, S. Sustainability indicators: report of the project on indicators of sustainable development. Chichester: John Wiley \& Sons Ltd, 1997.

DIAS, R. Marketing ambiental: ética, responsabilidade social e competitividade nos negócios. São Paulo: Atlas, 2007.

ENDERLE, G.; TAVIS, L. A. Balanced concept of the firm and measurement of its long-term planning and performance. Journal of Business Ethics, v. 17, n. 11, p. 1129-1144, 1998.

EPELBAUM, M. Sistemas de gestão ambiental. In: VILELA JR. Alcir. e DEMAJOROVIC, Jacques. Modelos e ferramentas de gestão ambiental: desafios e perspectivas para as organizações. São Paulo: Editora SENAC, 2006.

GASI, T. M. T.; FERREIRA, E. Produção mais limpa. In: In: VILELA JR. Alcir. e DEMAJOROVIC, Jacques. Modelos e ferramentas de gestão ambiental: desafios e perspectivas para as organizações. São Paulo: Editora SENAC, 2006.

INTERNATIONAL COUNCIL FOR LOCAL ENVIRONMENT INITIATIVES ICLEI. The local agenda 21 initiative. Toronto, 1994.

JACOBI, P. Educação ambiental, cidadania e sustentabilidade. Cadernos de pesquisa, n. 118, 2003, pp.189-205.

LA - ROVERE (Coord.). Manual de auditoria ambiental. Rio de Janeiro: Qualitymark, 2001. 
BARBOSA, M. de F. N.; RODRIGUES, D. G.; BARBOSA, M. E. Práticas Socioambientais...

MARTINS, M. de F.; CÂNDIDO, G. A. Índice de Desenvolvimento Sustentável para Municípios (IDSM): metodologia para cálculo e análise do IDSM e classificação dos níveis de sustentabilidade para espaços geográficos. João Pessoa: SEBRAE, 2008.

NASCIMENTO, L. F.; LEMOS, Â. D. da C.; MELlO, M. C. A. de. Gestão socioambiental estratégica. Porto Alegre: Bookman, 2008.

PHILIPPI JR., A.; AGUIAR, A. de O. Auditoria Ambiental. In: PHILIPPI JR., Arlindo; ALVES, Alaôr Café. Curso Interdisciplinar de Direito Ambiental. Barueri (SP): Manole, 2005.

QUAZI, A.; O'BRIEN, D. An empirical test of a cross-national model of corporate social responsibility. Journal of Business Ethics, v.25, 2000, pp. 33-51.

SACHS, I. Desenvolvimento sustentável, bio-industrialização descentralizada e novas configurações rural-urbanas: os casos da Índia e do Brasil. In: VIEIRA, Paulo Freire e WEBER, Jacques (Orgs.). Gestão de recursos naturais renováveis e desenvolvimento: novos desafios para a pesquisa ambiental. São Paulo: Cortez, 1997. cap. 15, pp. 469-494.

SÁNCHEZ, L. E. Avaliação de impacto ambiental e seu papel na gestão de empreendimentos. In: VILELA JR., Alcir e DEMAJOROVIC, Jacques (Org.). Gestão ambiental: desafios e perspectivas para as organizações. São Paulo: Editora Senac, 2006. cap. 3, pp. 85-104.

SEIFFERT, M. E. B. Gestão ambiental: instrumentos, esferas de ação e educação ambiental. São Paulo: Atlas, 2007.

SILVA, A. L. M. da. Direito do meio ambiente e dos recursos naturais. São Paulo: Editora Revista dos Tribunais, v. 1, 2004.

SIMONS, M. O. Educação ambiental na empresa: mudando uma cultura. In: VILELA JR. Alcir. e DEMAJOROVIC, Jacques. Modelos e ferramentas de gestão ambiental: desafios e perspectivas para as organizações. São Paulo: Editora SENAC, 2006.

SOUZA, E. G. de. Índice de Desenvolvimento Sustentável Municipal: uma análise a partir da articulação de atores sociais no município de Fagundes - PB. Dissertação (Mestrado em Recursos Naturais). Universidade Federal de Campina Grande - PB, 2011, p.159. 
BARBOSA, M. de F. N.; RODRIGUES, D. G.; BARBOSA, M. E. Práticas Socioambientais...

UK Departament of Environmental, Transport and Regions (Departamento do Meio Ambiente, de Transporte e das Regiões do Reino Unido) (1999).

VERGARA, S. C. Projetos e relatórios de pesquisa em administração. São Paulo: Atlas, 1997.

VOLTOLINI, R. Marketing ambiental: o consumidor verde influenciando a mudança de práticas mercadológicas nas empresas. In: VILELA JR., Alcir e DEMAJOROVIC, Jacques (Org.). Modelos e Ferramentas de Gestão Ambiental: desafios e perspectivas para as organizações. São Paulo: Editora Senac, 2006. cap. 13, pp.363385.

WOOD, D. Corporate social performance revisited. Academy of Management Review, v. 16, n. 4, 1991, pp. 691-718. 